\title{
SEXUAL SELECTION ON BODY SIZE, TERRITORY AND PLUMAGE VARIABLES IN A POPULATION OF DARWIN'S FINCHES
}

\author{
Trevor D. Price \\ Division of Biological Sciences, The University of Michigan, Ann Arbor, Michigan 48109
}

Received November 5, 1982. Revised May 9, 1983

Sexual selection on a phenotypic trait arises when that trait covaries with mating success among individuals of the same sex, usually males. As such sexual selection is thought to occur most readily and strongly in polygamous species where variance in mating success is high, but it can occur also in monogamous species where there is competition among males for early breeding females (Darwin, 1871 Ch. 8; O’Donald, 1980). As Darwin originally recognized, sexual selection in monogamous systems will be intensified when the sex ratio is skewed in favor of males. This paper reports on sexual selection on male body size, plumage and territory size characteristics in a small population of Darwin's Medium Ground Finches (Geospiza fortis) on I. Daphne Major, Galápagos, Ecuador. The species is monogamous, but during this study (from 1979 to 1981) males have outnumbered females by a factor of three to two.

\section{Theoretical Background}

The main purpose of this paper is to understand how the observed sexual selection, to be described below, arose and is maintained. To do this I first present a relevant theoretical classification of types of sexual selection (Table 1). The ultimate selection target (Table 1) is the character which give a selective advantage to discriminating females. If differences beween males in this character are not readily visible females are expected to use other cues to assess differences among potential mates. Thus characters actually observed to be under selection, the proximate selection target in Table 1, may differ from the ultimate selection target. Female preferences can be understood in terms of selection for male ge- netic quality, male parental care or for resources that males control. Male genetic quality has been subject to the most theoretical work, mainly because it is difficult to understand how genetic variance in male fitness can be maintained. One explanation ( $1 \mathrm{~A}$ in Table 1$)$ is that natural selection opposes the sexual selection, resulting in weak overall stabilizing selection (Fisher, 1958). An alternative model assumes that females choose males using as cues characters whose expression correlates positively with overall genetic quality (1B in Table 1). These characters can be termed facultative handicaps (Maynard Smith, 1976; Zahavi, 1977; Andersson, 1982). Facultative handicaps may be defined as characters whose degree of expression a) is used as a cue in mate choice, b) has an associated cost (to prevent cheating) and c) is not solely determined by genotype. Variance in overall male genetic quality can be maintained if different genotypes are of highest quality in different generations, although the maintenance of female mate preferences for the associated character requires that particular genotypes are favored in runs of several generations (i.e., positive autocorrelation, Hamilton, 1982; Hamilton and Zuk, 1982).

Despite the appreciation that in many polygamous species male genetic quality is the only factor which can be involved, the majority of demonstrations of sexual selection, especially those dealing with continuously varying traits, have been on phenotypic characters whose variance is largely environmental and often age-related (Howard, 1981; Johnson, 1982; McLain, 1982; papers in Blum and Blum, 1979; reviewed by Halliday, 1978). The sexual selection in such cases commonly 
TABLE 1. A classification of types of sexual selection.

Ultimate selection target

Proximate selection target

1) Male genetic quality:

A) offspring, once mature, will be favored as mates

B) offspring are expected to survive well and be favored as mates

A heritable character

A non-heritable character (facultative handicap)

2) Male parental care

A non-heritable character (facultative handicap)

3) Resources a male controls

The resources

arises from interactions among males and from female preferences for resources that dominant males control ( 3 in Table 1 ). Sexual selection based on resources or expected male parental care $(2$ in Table 1 ) is easy to understand. There is still the question, of particular importance in this study, of how genetic variance is maintained in a trait which cannot be interpreted as a facultative handicap, and which is found to be correlated with mating success. As discussed above, natural selection must be opposing the sexual selection or the trait must correlate sometimes positively and sometimes negatively with mating success.

\section{Scope of the Study}

The central part of this paper will be the observed selection on body size. Body size characters are highly heritable traits in this population (Boag and Grant, 1978; Boag, 1983). Therefore observed sexual selection has clear evolutionary implications. In addition, sexual selection occurred on plumage coloration and territory size. After demonstrating this, I will interpret the sexual selection on each variable in the theoretical framework of Table 1. All three variables are weakly correlated and the interpretations rest on a consideration of each character separately and when combined together.

There are just two species of finches breeding on I. Daphne, Geospiza fortis and $G$. scandens, the Cactus Finch. The present paper concerns G. fortis. Geospiza scandens was studied in less detail; results from this species are summarized in an Appendix, and referred to in the main body of the text where relevant.

\section{Methods}

The Darwin's finches on the 40 hectare island, Daphne Major, have been intensively studied over the years 1976-1981: in 1976-1978 by P. T. Boag (Boag, 1981) and subsequently by myself. A description of the island can be found in Grant et al. (1975) and Boag (1981). The island has been arbitrarily divided into $20 \mathrm{sec}$ tors (Boag, 1981). These sectors fall naturally into four groups based on habitat type and plant composition, particularly the relative abundance of Portulaca howellii, Opuntia echios and Bursera malacophylla. Comparisons of birds in these groups are used in some tests.

Finch Measurements. - Finches have been captured in mist nets throughout the study and five morphological measurements (three beak measures, wing chord, and weight) have been taken as described in Grant et al. (1975). Length measures were taken in millimeters and weight in grams. For many of the analyses beak depth is used as a measure of body size. This is justified because beak depth is highly correlated with other measures of body size, yet shows positive allometry with these measures and, most importantly, has low measurement error (Boag, 1981, 1983). All captured finches were released unharmed carrying a unique combination of color bands. By 1979, approximately $90 \%$ of all adult finches on the island were color banded $(N=217)$; by 1981 approximately $95 \%$ were color 
TABle 2. Estimated population sizes in March 1981, based on mapping pairs and territorial males on the island. The population is subdivided by cohort. The 1978 and 1979 columns give total numbers of birds hatched in those years and the 1976 column gives birds hatched in or before that year. There were no survivors from 1977 or 1980 .

\begin{tabular}{lccccc}
\hline & 1976 & 1978 & 1979 & $\begin{array}{c}\text { Unknown } \\
\text { age }\end{array}$ & Total \\
\hline Males & 69 & 75 & 6 & 0 & 150 \\
Females & 24 & 41 & 11 & 3 & 79 \\
\% males & 74 & 65 & 35 & 0 & 66 \\
\hline
\end{tabular}

banded (population sizes are given in Table 2).

Finch Breeding.-Geospiza fortis breeds in response to rainfall which falls erratically between January and June (Grant and Boag, 1980). In 1977 there was a drought resulting in no successful breeding and heavy adult mortality (Grant and Grant, 1980; Boag and Grant, 1981). The population sizes in the period 1979-1981 have subsequently been so small that virtually all nests producing fledged young have been detected; e.g., only two out of $190(1 \%)$ were missed in 1981. All males build nests whether mated or unmated. These nests were marked and the males' mates, if any, were recorded. Active nests were checked at two to eight day intervals and information on clutch size and hatching and fledging success was collected. Chicks were color banded when eight days old. For present purposes a chick was assumed to have successfully fledged if it reached this age, provided there was no evidence of subsequent mortality in or around the empty nest after this date. Laying and hatching dates were either directly observed or extrapolated from chick development.

Plumage and Territory Measurements. - Variation in plumage arises because young males resemble females, as commonly occurs in many sexually dichromatic species (Darwin, 1871 Ch. 16; Rohwer et al., 1980). The rate of acquisition of black (adult) plumage varies considerably among individuals (Fig. 1). In this study some males had scarcely
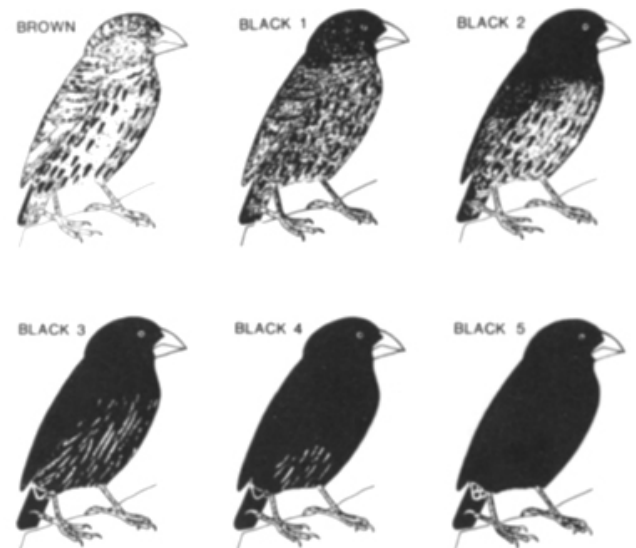

Fig. 1. Categorization of plumage types. Males progress from the female-like plumage (Brown) in sequence from Black-1 to Black-5. Black-5 is referred to in the text as full adult plumage.

acquired any black when three years old while others have been in virtually full adult plumage within 15 months of hatching. Once acquired, black plumage is never lost either seasonally or across years. In each year the amount of black plumage in each singing male was recorded on an integer scale of one to five (Fig. 1). Territories were delineated by the area over which males sang and by border displays. Territory size was measured in 1981, using a series of markers placed at $20 \mathrm{~m}$ intervals over the whole island. The presence or absence of important food plants in each territory was recorded.

\section{RESULTS}

There are two different levels at which sexual selection can be studied. The first is to obtain an indication of the potential for sexual selection through behavioral observations of pair formation and comparisons of variance in mating or reproductive success between sexes or among populations and species (Payne and Payne, 1977; Wade and Arnold, 1980; Payne, in press). The second is the direct observation and interpretation of sexual selection on a phenotypic character when that character correlates with differential 
TABLE 3. Statistics on the mean and variance in mating and fledging success among males in each of three years. $N$ : the number of color banded territorial males. $N m$ : the number of these males mated for at least part of the season. $V s$ : the binomial variance in mating success for males. $I s$ : the squared coefficient of variation in mating success among males. $\bar{x}$ : mean number of chicks fledged per male. Im: squared coefficient of variation in the number of fledged chicks per male. If: the equivalent measure among females. The quotients $I \mathrm{~s} / \mathrm{Im}$ and $I \mathrm{~m} / \mathrm{If}$ are elaborated on in the text.

\begin{tabular}{cccccccrcrc}
\hline \hline Year & $N$ & $N m$ & $V_{s}$ & $I s$ & $\bar{x}$ & $I m$ & \multicolumn{1}{c}{ If } & Is/Im & Im/If \\
\hline 1979 & 82 & 54 & .21 & .49 & .93 & 2.11 & .88 & .23 & 2.4 \\
1980 & 158 & 64 & .24 & 1.48 & .13 & 15.60 & 5.57 & .09 & 2.8 \\
1981 & 142 & 85 & .24 & .68 & 1.93 & 1.12 & .14 & .62 & 8.0 \\
\hline
\end{tabular}

mating success. Both levels will be considered here in turn.

\section{Pair Formation}

Immediately after rainfall, usually in January or February, territories are expanded so that in the more densely settled areas there are well defined boundaries. Males build nests. Although experienced pairs may remain associated, it is only at this time that inexperienced females first acquire mates. Unmated females arriving on territory are chased in long twisting flights over and off the territory (sexual chases, e.g., Ratcliffe, 1981) and may return, eventually to build with the male. Within a few days of pairing off the male may be regularly feeding the female and eggs are usually laid between eight days and one month later. Sexual chases also commonly occur between members of pairs that have been long mated.

Copulations Outside the Pair Bond.Females generally solicit copulations only from their own mates. I have once observed a female mating with a neighboring male. This occurred after her mate (a newly mated male) failed to respond. Males do not often attempt to restrict the movements of their females, and even during egg laying many females spend a substantial time off their territory (see below).

Males regularly display to females to whom they are not mated, both on and off territory, and mated males may even establish temporary second territories while their females are incubating. When confronted by such males females fly off, or if on their own territory peck at the displaying male while awaiting the return of their mate to copulate. In such situations I have observed three attempted copulations on the back or wing of the female.

Mate Switches. - Some females change mates between breeding bouts. Between 1980 and 1981 , ten (18\%) did so although at least four of these attempted to breed with their original male; in each case the original male lost all or part of his territory to an unmated neighbor and the female then bred with the neighbor. Three other cases involved movement of over $200 \mathrm{~m}$ by the female and cannot be so explained.

The observations indicate that territorial interactions between males can influence mating success, but point to a significant role in mate choice for the females, who can and do visit several territorial males before pairing.

\section{Variance in Mating and Fledging Success}

Differential mating success among males is an indication of the potential for sexual selection and can be quantified using the techniques of Wade and Arnold (1980; see also Payne, in press). Mating success for a male is here defined as the presence or absence of a mate. As a consequence of the skewed sex ratio (Table 2) many males remained unmated, and none were mated bigamously.

Statistics on the mean and variance for various measures of reproductive success 
TABLE 4. Sexual selection on beak and body size. ${ }^{*}=P<.05, * *=P<.01$, and ${ }^{* * *}=P<.001$ by two tailed $t$ tests conducted on $\log$ transformed data to eliminate scale effects. The variances did not significantly differ in any comparison (Levene tests). See text for further details of the column headings. All entries for character values are means.

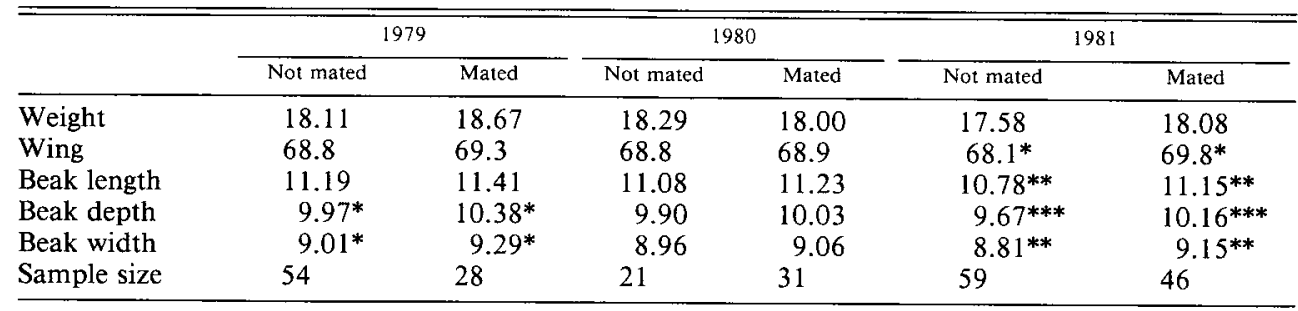

are given in Table 3 . The binomial variance in mating success $(V S)$ is close to .25 , the highest possible in a monogamous mating system. Is, the squared coefficient of variation in mating success, gives an approximate measure of the total opportunity for selection on a phenotypic trait (Wade and Arnold, 1980). The squared coefficient of variation in fledging success, $I m$, gives a measure of variation in overall reproductive success for the males. Thus the quotient $I s / I m$ gives the proportion of the variance in fledging success that is directly attributable to variance in mating success (Wade and Arnold, 1980). In a year of high fledging success (e.g., 1981, Table 3) this may be very high.

Squared coefficients of variation in fledging success among females (If) are also given. The quotient $I m / I f$ is always greater than unity (Table 3 ), confirming that the greater variance in mating success for males is translated into greater variance in more direct measures of reproductive fitness, and that the potential for sexual selection is higher among males than among females.

Both the behavioral observations and the large number of males that remain unmated suggest that female choice of males is likely to be exercised to a far greater extent than male choice of females.

\section{Sexual Selection on Beak and Body Characters}

In this section I demonstrate sexual selection on body and beak size by com- paring the morphological traits of newly mated and unmated males. To avoid ambiguities, a pair is considered to be newly mated at the time when the first eggs are laid. In addition I have included two pairs that were known to be together for two years before their first clutch was laid. The morphometrics are presented in $\mathrm{Ta}$ ble 4 for three time periods, henceforth named by year. The 1979 column compares all unmated adult males with those mated in January of that year. No two members of a pair breeding in 1976 were known to survive a drought in 1977 ; therefore the 1979 column rerpesents new matings in 1978 , with a reassortment of an estimated three or four mates in 1979. The breeding data from 1979 are used instead of 1978 because there was a higher proportion of color-banded birds in that year and because the population was more thoroughly studied. The 1980 column compares those males that had acquired mates between January 1979 and April 1980 (mostly in May 1979) with those that remained unmated; however twoyear-old males are excluded in this comparison because so few $(12 \%)$ acquired mates. The 1981 column is a comparison of newly mated with unmated males.

Table 4 shows that strong directional sexual selection for large size occurred in two out of the three years. All traits show the same trend, although statistical signifiance varies: this is partly a reflection of differing measurement error among traits (Boag, 1983).

Size Correlated Dominance.-One common explanation for sexual selection 
is that larger males are dominant over smaller males and control resources such as food and nest sites that females prefer (Selander, 1972; Searcy, 1979a, 1979b). Dominance is difficult to observe directly in nature. Accordingly I induced a total of 232 interactions at an artificial food source (bread crumbs) and recorded displacements of one bird by another. The median size of birds dominated by an individual (in beak depth or in body weight) was as often larger as smaller than the individual dominating $(N=19: 8$ larger, 9 smaller, with two ties). Experiments are likely to be inconclusive because of uncontrolled variables such as the different motivational states of the birds. To the extent that these observations are applicable to dominance at the time of territory establishment, they give no support to the idea of size-correlated dominance. However studies on other bird species have demonstrated size-correlated dominance (Baker and Fox, 1978; Searcy, $1979 b$ ). Size related dominance certainly operates interspecifically on Daphne with larger congeners rarely being displaced by smaller ones, and may operate intersexually, for there was far greater mortality of females than males over a drought in 1977 (Boag and Grant, 1981).

If females choose males on the basis of their resource holdings it should be possible to identify these resources. Territory quality has been shown to be a major determinant of mate choice in several polygamous species (e.g., Pleszcynska, 1978; Searcy, 1979c; Wittenberger, 1981). Nest predation risks, potential shade for the open nest and food supply have been considered potentially important variables. In the present study successful nest predation has never been known to occur. Potential shade is difficult to measure, but is unlikely to be important because all finch nests are domed and built deep in Opuntia bushes.

I consider the possible importance of food supply first in enabling females to accumulate resources for laying eggs, and second in the feeding of nestlings. Territories nearly always include Opuntia cactus, in which $99.8 \%$ of all nests have been built, but once the Opuntia has stopped flowering in February, it is not an important food source for many females, and pairing up occurred after this time in 1980 and 1981. In 1981 Opuntia area in territories did not correlate with laying date among newly formed pairs $(N=32, r=-.13, P>.5)$. Over half the island was not defended by territorial males but birds regularly foraged there. Females commonly foraged off territory throughout the breeding cycle. Prior to laying males do feed females on pre-rains food such as Opuntia seeds found mainly on territory, but these seeds have been abundant throughout the study (Millington and Grant, 1983).

Both sexes regularly foraged off territory when feeding nestlings or recently fledged young. In 1981, in 33 continual watches for $30 \mathrm{~min}$ of males or females that were feeding nestlings or fledged young, an average of $13.5 \mathrm{~min}(45 \%)$ was spent off the pair's own territory.

Portulaca howellii is the single most important food source during the breeding season, providing pollen, seeds and caterpillars (Boag, 1981), but it occurs in large areas out of territories and is found in just $60 \%$ of all territories. Portulaca seeds or pollen were found in $72 \%$ of all nestling crops examined in $1981(N=$ 109) and occurred as often in territories with Portulaca as without $\left(\chi^{2}{ }_{1}=.25, P=\right.$ $.8)$. In 1979 and 1981 there was no difference in mating success between males with and without Portulaca on their territories (1979: $N=82, \chi^{2}{ }_{1}=.85, P=.4$; 1981: $\left.N=114, \chi_{1}^{2}=.02, P=.9\right)$. In 1980 the presence of Portulaca correlated with the chances of obtaining a mate $\left(N=52, \chi_{1}^{2}=4.55, P=.03\right)$. Much of the 1980 pairing took place in May 1979 , i.e., late in the season when Portulaca had flowered and seeded and females were commonly foraging in it. By contrast, the bulk of pairing in the 1979 and 1981 comparisons occurred when females were foraging on pre-rains food and on food (notably shoots of annual plants) that responded rapidly to the first rains. Both these food types are distributed more 
evenly over the whole island, occurring abundantly in and out of territories.

I conclude that I cannot identify resources that distinguish territories that females might prefer. This is in contrast to $G$. scandens where Opuntia in territories appears to be an important resource (Millington and Grant, 1983; Appendix).

Active Female Choice. - A second possibility for the sexual selection is that females actively, regularly, choose males on the basis of morphology (i.e., 1 $\mathrm{A}$ in Table 1). In principle the possibility of active female choice is directly testable because there should be a genetic correlation between mate preference and the preferred male character (Lande, 1981). In one test for such an association I found no correlation between females' fathers and their mates for any morphological trait (for beak depth $r=.082, N=19$ ). However the expected magnitude of this correlation depends on the extent of heritable variance in mate choice and may be very small, and its measurement is likely to be obscured by proximate ecological factors. Negative evidence is not compelling.

Male Quality. - Both mechanisms of sexual selection discussed above arise from size differences between males which are assessed either intrasexually (by males) or intersexually at the time of pair formation. There is evidence for another effect: those males with recent high survival probability were favored as mates. The two years (1979 and 1981) in which sexual selection was observed followed periods of heavy $(85 \%)$ and moderate $(20 \%)$ adult mortality, respectively. Periods of adult mortality have been accompanied by selection for large size (Boag and Grant, 1981). Thus females have exercised a preference for large males at just those times when large size was correlated with survival in the pre-mating period. In 1980 little sexual selection in $G$. fortis was observed and there had been very little adult mortality (hence no detectable natural selection) in the two years previously.
The natural selection for large size has been interpreted as due to the superior large seed handling ability of larger individuals. This may be important in itself because males feed large seeds to the females in the pre-laying period, although large seeds are not commonly fed to nestlings (Boag, 1981). Alternatively the higher survival probability of larger males may be reflected in a higher quality persisting throughout the breeding season. Consideration of the role of selection on other male characters lends support to the idea that male quality is involved in the sexual selection for body size.

\section{Territory Size}

Despite the absence of identifiable resources in territories which could provide a basis for mate choice, territory area per se, measured in 1981 only, was found to be an important predictor of mating success (probit analysis [Hanushek and Jackson, 1977] using log area, $N=93$, $\chi_{1}^{2}=14.26, P=.0002$ ). This trend was observed within each of the four habitat types on the island, and was significant in three of these areas.

A very high correlation for territory area was found among male sibs. Sib-sib correlations can be used as an estimate of half the heritability of a character, although this estimate will be inflated (Falconer, 1981). The intraclass correlation coefficient in a one-way analysis of variance of full sib families using those males hatched in 1978 , is $r=.50(F[11,21]=$ $3.73, P<.01)$. Part of this correlation may arise because there is a correlation between body size and territory size (see below, Table 6), and body size is heritable. The effects of body size were removed by regressing territory size on beak depth and repeating the analysis using the residuals from the regression. This gave $r=.43(F[11,20]=2.95, P<.05)$. The correlation remains. The correlation does not arise out of a tendency of brothers to settle in similar habitats. When the island is divided into four parts only four pairs of brothers settled in the same area.

The above results were not anticipated. 
It is worth noting that territory area is determined anew at the beginning of each breeding bout. Neighbors, but not time of settlement, are likely to strongly influence this variable.

\section{Selection on Male Plumage}

All the males that fledged in or before 1976 were in or close to full adult plumage by 1981 . Since many of the males from the 1978 and 1979 cohorts still retained some sub-adult plumage, adult plumage is on the average an indicator of age. The differential rate of acquisition of black plumage among members of the 1978 and 1979 cohorts (relative numbers in Table 2) resulted in a large variance to this character among birds breeding in 1980 or 1981 . In 1981 females preferred males from these cohorts with more black in their plumage. Although plumage was recorded on a $1-5$ scale (Fig. 1) there were very few birds in the lowest plumage classes in 1981, and for comparisons in that year I used presence or absence of full adult plumage (Black-5 in Fig. 1) as the variable in all statistical tests. Fifty five percent $(N=55)$ of the fully black males in the 1978 and 1979 cohorts obtained mates, whereas $29 \%(N=63)$ of the males in some sub-adult plumage did so. The difference is significant $\left(\chi^{2}=8.15\right.$, $P=.004)$. With these data only a crude estimate of the sib-sib correlation for 1978 hatched males in 1981 can be obtained. In a one-way ANOVA the intraclass correlation coefficient was $r=.24$, $F(11,22)=1.9, P=.1$, although the assumptions for statistical testing are violated.

\section{Female Choice of Body Size, Territory Size and Plumage Combined}

The separate results on body size, territory size and plumage for 1981 are summarized in Figure 2. In this section I regress the dichotomous variable, male mating success, on these three characters to determine the relative strengths of selection acting directly on each character, following the methods of Lande and Arnold (1983; Table 5). Mating success was
TABLE 5. Standardized partial regression coefficients $(\beta) \pm$ standard error when relative mating success is regressed on beak depth, territory size and plumage. The $R^{2}$ value for the regression and sample size (with the number of males obtaining mates in parentheses) are given. The column headed adult males is a comparison of those males, at least two years old, which acquired mates in 1981 with those which remained unmated. The column headed 1978 males is a similar comparison for those males hatched in 1978 which acquired mates in 1980 or 1981 with those that did not. ${ }^{* *} P<.01$.

\begin{tabular}{lcc}
\hline \hline & Adult males & 1978 males \\
\hline Beak depth & $\beta \pm \mathrm{SE}$ & $\beta \pm \mathrm{SE}$ \\
Territory area & $.26 \pm .10^{* *}$ & $.40 \pm .14^{* *}$ \\
Plumage & $.30 \pm .10^{* *}$ & $.24 \pm .14$ \\
$R^{2}$ & $.24 \pm .10^{* *}$ & $.26 \pm .14$ \\
Sample size & $92(43)$ & $.26^{* *}$ \\
\hline
\end{tabular}

scaled such that mean relative mating success equalled one. Log beak depth, log territory area and plumage recorded as presence or absence of full adult plumage were separately standardized to have zero mean and unit variance. In a preliminary stepwise multiple regression analysis other measures of body size and territory quality only entered after these measures, and then did not contribute significantly. All significance levels were checked using probit analysis (Hanushek and Jackson, 1977).

All three variables are individually under highly significant directional selection of similar intensity (Table 5). If territory size and plumage are added first to the model, the significance of beak depth is reduced from $P=.001$ to $P=.01$. This is because beak depth is correlated with both territory area and plumage (Table $6)$.

A second analysis was performed to determine the effects of the selection on just the 1978 cohort of males. Males from this cohort that acquired mates in either 1980 or 1981 were compared with those that did not (Table 5). Males from this cohort had significantly smaller territories than older males $(N=123, t=3.3$ $P=.001)$ although they were not signif- 

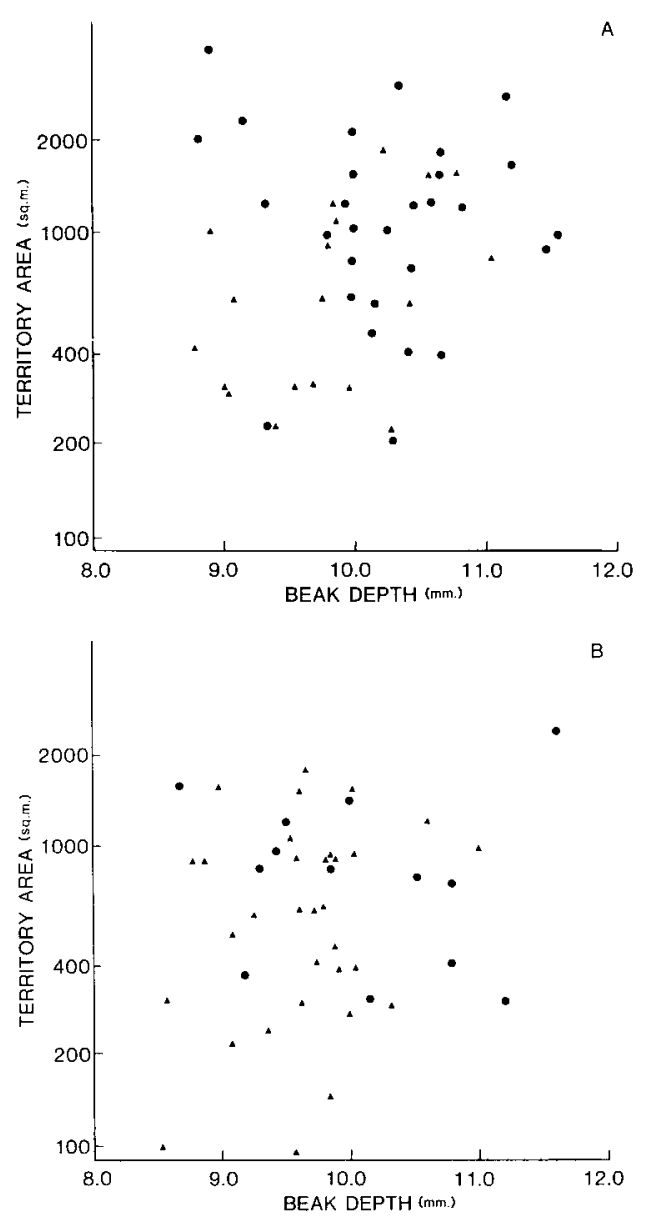

FIG. 2. The contributions of beak depth and territory area to mating success. Symbols: mated males, $\Delta$ unmated males. A) Males in full adult plumage. B) Males retaining some juvenile plumage.

icantly smaller in beak depth $(N=130$, $t=1.6, P>.05$ ). Beak depth is the only character under significant selection. There is no significant selection acting directly on plumage or territory size $(P>$ .1 in each case). Associations of beak depth with territory area and plumage are not significant (Table 6).

\section{Male Quality}

The question remains as to what benefits females gain by choosing particular males. Here I consider the possibility of
TABLE 6. Pearson product moment correlations between $\log$ territory area and beak depth, and Spearman rank correlations between these characters and plumage. The samples are as in Table 5, with adult males below the diagonal and 1978 males above the diagonal. ${ }^{*} P<.05$.

\begin{tabular}{lccc}
\hline \hline & Beak depth & $\begin{array}{c}\text { Territory } \\
\text { area }\end{array}$ & Plumage \\
\hline Beak depth & & .14 & .16 \\
Territory area & $.23^{*}$ & & .14 \\
Plumage & $.28^{*}$ & $.23^{*}$ & \\
\hline
\end{tabular}

choice based on parental care that males will provide. The character most obviously indicating male quality is plumage: experienced males are likely to be the best parents and might be identified by their adult plumage.

However, a general difficulty arises with any tests because most males with nonpreferred characters remained unmated, hence their contribution to parental care cannot be assessed. It is also empirically difficult to assess contributions to parental care by those males that do breed. The rate of feeding nestlings and females prior to laying and during incubation can be observed but the amount of food per feeding, which varies substantially (Downhower, 1978), cannot. In fact there are small positive non-significant correlations of fledging success with territory size (probit analysis, $N=44, \chi^{2}{ }_{1}=.8$, $P=.7$ ), and with the proportion of adult plumage in males (Spearman's rank correlation $=.14, P>.5$ ). Similar results are obtained when total nestling mass at age eight days or laying date are substituted for fledging success. Trends, if they exist, are likely to be obscured by a large random element to fledging success, compounded by female contributions to fledging success. One trend that can be examined independently of females is the proportion of the brood fed by the male once they have fledged. This is probably important because in this study females only renested if they were feeding one or no chicks. Again there is a trend towards the blacker males taking a greater part in parental care, but it is not possible to test 
for significance. Figure 3 shows these data for males in 1981 .

\section{DisCUSSION}

\section{The Potential for Sexual Selection}

In the $G$. fortis population studied here there was high potential for sexual selection as measured by variance in mating and fledging success. These measures approach those observed in some polygamous systems (cf. Payne, in press). Using the methods of Wade and Arnold (1980) it was shown that about $50 \%$ of all variance in fledging success was attributable to having a mate.

Even though a high observed potential for sexual selection may often be observed, it is not always meaningful. Very high coefficients of variation in mating and fledging success in 1980 were of no selective importance because all offspring died within one month of fledging in that year. Further, differences between years and between $G$. fortis and $G$. scandens in the potential for sexual selection (Appendix) do not correlate well with the intensities of selection acting on body size. Measures of the potential for sexual selection can only provide a crude approximation to its evolutionary importance. A similar conclusion has been reached from a large number of inter-species comparisons (Payne, in press).

\section{Selection on Territory Size}

I now consider the observed selection on each of the three phenotypic traits. I begin with the observed selection on territory size because the results are clearly interpretable in terms of the theory (Table 1). The main results for this character are (1) territory size per se is important in mate choice and (2) sib-sib correlations for territory size are high.

The large difference in territory size in 1981 between males from the pre-1976 and from the 1978 cohorts, as well as an obvious immediate cost in maintaining a large territory, suggest that territory size is a facultative handicap ( $1 \mathrm{~B}$ and 2 in

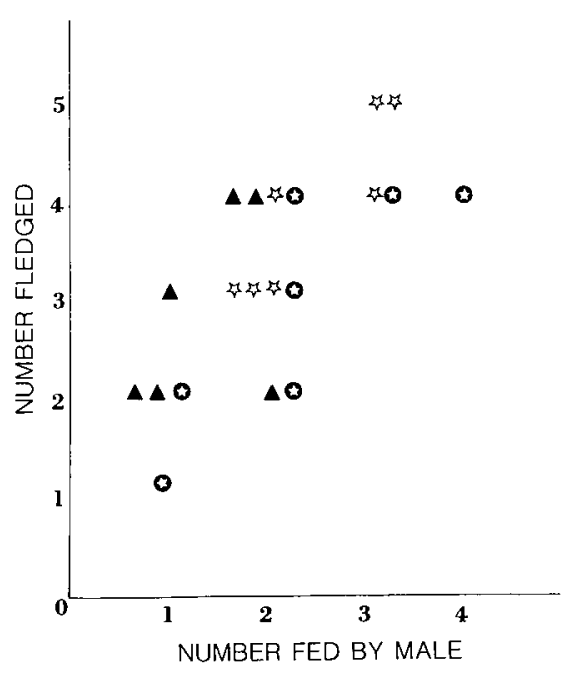

FIG. 3. Number of fledglings in a brood compared with the total number of chicks fledged. $\Delta$ a male with some juvenile plumage, $t>$ a male in full adult plumage. The circled points are those where the female laid a second clutch: note that only females mated to males in full adult plumage had a second clutch.

Table 1), correlating with aspects of male quality, rather than directly genetically determined. Although heritability estimates using full sibs are inflated by the presence of dominance and common environment effects (Falconer, 1981) the high estimates imply the presence of some additive genetic variance. However, as argued below, although the male quality may be genetically based, the sexual selection itself may be based on potential parental care rather than on genetic contributions to offspring.

Whatever the underlying cause, territory size is a trait under sexual selection in this population. Territory size per se has been shown to be an important component of mating success in Arctic Skuas, Stercorarius parasiticus (Davis and O'Donald, 1976), and in several polygamous species territory size is correlated with the number of females a male secures as mates (Armstrong, 1955; Balfour and Cadbury, 1980). Sexual selection is a simple and general explanation for breeding season 'superterritoriality' dis- 
cussed by Verner (1977). Similar ideas have been advanced by O'Donald (1977).

\section{Selection on Plumage Variation}

Several recent studies have demonstrated that males with a greater proportion of the adult coloration in their plumage are favored as mates (Proctor-Gray and Holmes, 1981; Edwards, 1982; Payne, 1982). In this study males known to be from the same age cohort were consistently at a mating disadvantage when in sub-adult plumage, and the same result was found for G. scandens (Appendix). Since sub-adult and adult territories are interdispersed, this is not expected from the hypothesis that presence of female-like plumage is an adaptation that enables young males to improve their chances of obtaining a mate (Rohwer et al., 1980).

The alternative to an adaptive hypothesis is that the acquisition of adult plumage is an indication of male quality. This implies there is a cost associated with adult plumage acquisition. One possibility is that plumage variation reflects underlying hormonal variation with associated behavioral costs (Davis and O'Donald, 1976; Rohwer and Rohwer, 1978). Males may also react more aggressively to other males in full adult plumage, simply because these males represent a greater threat to their chances of obtaining a mate.

Sexual selection on plumage variability is more likely to arise out of its general indication of male age than its phenotypic handicap value. Older males could be chosen either for their genetic quality (as indicated by their continued survival) or estimated greater past breeding experience. There are some indications that males in full adult plumage contribute more parental care (Fig. 3), than those in sub-adult plumage.

A possible genetic contribution remains unassessed. However, corresponding to a decline in active territorial defense, territory size and plumage are both characters that are likely to be costly at the time of pair formation, less costly when feeding their mates and hardly at all when feeding young. They thus appear particularly suitable as indicators of potential parental care.

\section{Selection on Body Size}

The selection on body size is the most difficult to classify into clearly defined alternatives. I consider each of the possibilities outlined in Table 1 in turn. Both schemes 1A and 1B in Table 1 are based on the idea that large body size is chosen because it is heritable, and there is an advantage to having large offspring. In contrast under schemes (2) and (3) the sexual selection arises because it correlates with future male parental care or resources males control.

(1A) Preferences for males are maintained by the mating advantage of their sons. The preferences could have arisen out of a selective advantage in avoiding heterospecific matings, for female Geospiza are known to use beak and body morphology to distinguish among congeners (Lack, 1947; Ratcliffe and Grant, 1983). One implication of this hypothesis is that large males are at a net disadvantage under natural selection over a whole life cycle. The optimum body size under natural selection averaged over several generations is unknown.

(1B) Body size could be under both directional sexual and natural selection over a whole life cycle in males. Once adult, males have been shown to be under natural selection for large body size (Boag and Grant, 1981). The hypothesis is that females choosing males with high survival probability have sons which on average also survive well. This implies that small body size will be naturally and sexually selected in other generations, and females choose 'facultative handicaps' (discussed below) that indicate male genetic quality. This scheme appears unlikely because 1) there is no evidence for the required positive autocorrelation in environmental conditions which favor large size and 2) it is not clear that over 
a whole life cycle large males are at a survival advantage (Price and Grant, unpubl.).

There is a general argument against the sole importance of schemes (1) in comparison with (2) and (3) below. If male genetic quality were of major importance, females paired with inferior males might be expected to regularly 'steal copulations' from higher quality males. This is not observed.

(2) Females choose on the basis of male quality because of the expected higher contribution to parental care (including feeding of the mate) high quality males will make. One implication is that at present large size correlates with male quality, which might be expected because large size correlated with survival probability in the period immediately prior to breeding. Females choose males using facultative handicaps. Territory size and plumage have been identified from a multiple regression as two possible facultative handicaps correlated with body size, and some of the body size selection can be explained as resulting from selection for these two characters. In addition unmeasured components (e.g., song rate, Greig-Smith [1982], and persistence in sexual chases) may also be involved.

There is a substantial contribution of body size to mating success after the effects of territory size and plumage have been removed, especially within the 1978 cohort of males. Therefore if scheme (2) is to account for much of the selection, other cues of quality correlated with body size must be important, or alternatively females may use body size as a direct clue to quality in some years.

(3) There is the possibility of sexual selection on body size independent of any correlation with male quality. Under this hypothesis large males are dominant and control resources that females prefer. Although potentially important resources could not be identified, territory size is a variable directly involved in mate choice that could be affected by size-related dominance. If territory size correlates with body size, and independently with previous male survival probability, then both types of selection (2) and (3) on body size could arise from females preferring those males with high survival probability and using territory size as a cue.

If natural selection is found to favor small adult size just prior to breeding in a future year then the expected directions of sexual selection differ under the schemes (2) and (3) and the relative importance of the two may be separated.

In summary, the interpretation of the observed selection on all three characters which has the most support is that plumage variation and territory size are facultative handicaps chosen for their indication of underlying male quality. Body size is partly selected because it correlates with quality at present. Quality is likely to be realized in the contributions a male makes to parental care and possibly to some extent genetically to the offspring. Other types of sexual selection on body size are also likely to be involved.

\section{SumMary}

The population of Medium Ground Finches (Geospiza fortis) on I. Daphne Major, Galápagos was studied between 1979 and 1981. During this period adult males outnumbered females by two or three to one as a result of differential mortality during a drought in 1977. The skewed sex ratio resulted in a high potential for sexual selection in this monogamous species: about half the variance in male reproductive success was attributable to variation in mating success. Females preferred to mate with larger males in two out of three years. Territory size and extent of adult plumage were also found to be positively correlated with mating success, and all three characters contributed significantly when combined into a regression model using probit analysis.

The main conclusions for each of the three characters treated separately are as follows. Plumage and territory size characters are tentatively interpreted as being 
indicators to females of male quality. High quality males probably contribute increased parental care and possibly genetic quality to their offspring. I find no evidence that sub-adult plumage has adaptive value with respect to mating success. Territory size may be a sexually selected trait more commonly than is generally assumed and sexual selection may prove to be a general explanation for 'superterritoriality.' Body size was under selection in part because it positively correlated with male quality; other types of sexual selection (active female preferences and male-male competition) may also be operating.

\section{ACKNOWLEDGMENTS}

My thanks to Spike Millington and Ayse Unal for companionship on Daphne, and to Peter Grant for advice throughout, and drawing the birds. P. T. Boag, J. F. Downhower, H. L. Gibbs, W. D. Hamilton, R. Lande, S. Rohwer, D. Schluter, P. E. Smouse and M. Zuk commented on the manuscript. This research was funded by NSF grants DEB-77-23377 and DEB-79-21119 to P. R. Grant, with some additional support from the Chapman Fund.

\section{Literature Cited}

ANDERSSON, M. 1982. Sexual selection, natural selection and quality advertisement. Biol. J. Linn. Soc. 17:375-393.

Armstrong, E. A. 1955. The Wren. Collins, London.

BAKER, M. C., AND S. F. Fox. 1978. Dominance, survival, and enzyme polymorphism in Darkeyed Juncos, Junco hyemalis. Evolution 32:697711.

Balfour, E., and C. J. Cadbury. 1980. Polygyny, spacing and sex ratio among Hen Harriers Circus cyaneus in Orkney, Scotland. Ornis. Scand. 10:133-141.

Blum, M. S., AND N. A. Bцum, eds. 1979. Sexual Selection and Reproductive Competition in Insects. Academic Press, N.Y.

BoAG, P. T. 1981. Morphological variation in the Darwin's Finches (Geospizinae) of Daphne Major Island, Galápagos. Ph.D. thesis. McGill Univ. 1983. The heritability of external morphology in Darwin's finches (Geospiza) on Isla Daphne Major, Galápagos. Evolution 37:877894.
BoAg, P. T., And P. R. GRant. 1978. Heritability of external morphology in Darwin's finches. Nature 273:793-794.

-. 1981. Intense natural selection in a population of Darwin's finches (Geospizinae) in the Galápagos. Science 214:82-85.

Darwin, C. R. 1871. The Descent of Man and Selection in Relation to Sex. John Murray, London.

Davis, J. W. F., AND P. O'Donald. 1976. Territory size, breeding time and mating preference in the Arctic Skua. Nature 260:774-775.

DOWNHOWER, J. F. 1978. Observations on the nesting of the Small Ground Finch Geospiza fuliginosa and the Large Cactus Finch $G$. conirostris on Espanola, Galápagos. Ibis 120:340346.

EDWARDS, P. J. 1982. Plumage variation, territoriality and breeding displays of the Golden Plover, Pluvialis apricaria in southwest Scotland. Ibis 124:88-95.

FALCONER, D. S. 1981. Introduction to Quantitative Genetics, 2nd ed. Longman, N.Y.

FISHER, R. A. 1958. The Genetical Theory of Natural Selection, 2nd ed. Dover, N.Y.

Grant, P. R., AND P. T. Boag. 1980. Rainfall on the Galápagos and the demography of Darwin's finches. Auk 97:227-244.

Grant, P. R., AND B. R. Grant. 1980. Annual variation in finch numbers, foraging and food supply on Isla Daphne Major, Galápagos. Oecologia 46:55-62.

Grant, P. R., And T. D. Price. 1981. Population variation in continuously varying traits as an ecological genetics problem. Amer. Zool. 21:795811.

Grant, P. R., J. N. M. Smith, B. R. Grant, I. AвBOTt, AND L. K. AвBOtT. 1975. Finch numbers, owl predation and food supply on Isla Daphne Major, Galápagos. Oecologia 19:239_ 257.

Greig-Smith, P. W. 1982. Song rates and parental care by individual male Stonechats (Saxicola torquata). Anim. Behav. 30:245-252.

HaLlidAY, T. R. 1978. Sexual selection and mate choice, p. 180-203. In J. R. Krebs and N. B. Davies (eds.), Behavioural Ecology: an Evolutionary Approach. Sinauer, Sunderland.

Hamilton, W. D. 1982. Pathogens as causes of genetic diversity in their host populations, $p$. 269-290. In R. M. Anderson and R. M. May (eds.), Population Biology of Infectious Disease Agents. Dahlem Konferenze, 1982. Verlag Chemie, Weinheim.

Hamilton, W. D., AND M. Zuk. 1982. Heritable true fitness and bright plumage in birds: a role for parasites? Science 218:384-387.

HanusheK, E. A., AND J. E. JACKSON. 1977. Statistical Methods for the Social Sciences. Academic Press, N.Y.

Howard, R. D. 1981. Male age size distribution and male mating success in bullfrogs, p. 61-77. In R. D. Alexander and D. W. Tinkle (eds.), 
Natural Selection and Social Behavior. Chiron Press, N.Y.

JOHNSON, L. K. 1982. Sexual selection in a brentid weevil. Evolution 36:251-262.

LACK, D. 1947. Darwin's Finches. Univ. Press Cambridge, Cambridge.

LANDE, R. 1981. Models of speciation by sexual selection on polygenic traits. Proc. Nat. Acad. Sci. 78:3721-3725.

LANDE, R., AND S. J. ARnold. 1983. The measurement of selection on correlated characters. Evolution 37:1210-1226.

Maynard Smith, J. 1976. Sexual selection and the handicap principle. J. Theoret. Biol. 57:239242.

MCLAIN, D. K. 1982. Behavioral and morphological correlates of male dominance and courtship persistence in the blister beetle Epicauta pennsylvanica (Coleoptera:Meloidae). Amer. Midl. Nat. 107:396-403.

Millington, S. J., and P. R. Grant. 1983. Feeding ecology and territoriality of the Cactus Finch Geospiza scandens on Isla Daphne Major, Galápagos. Oecologia 58:76-83.

O'DonALD, P. 1977. Sexual selection and the evolution of territoriality in birds, p. 113-129. In F. B. Christiansen and T. M. Fenchel (eds.), Measuring Selection in Natural Populations, Lecture Notes in Biomathematics. Springer-Verlag, N.Y.

- 1980. Sexual selection by female choice in a monogamous bird: Darwin's theory corroborated. Heredity 33:1-16.

PAYNE, R. B. 1982. Ecological consequences of song matching: breeding success and intraspecific mimicry in Indigo Buntings. Ecology 63: 401-411.

- In press. Sexual selection, lek and arena behavior and sexual size dimorphism in birds. Ornithol. Monogr.

Payne, R. B., And K. Payne. 1977. Social organization and mating success in local song populations of Village Indigobirds, Vidua chalybeata. Z. Tierpsychol. 45:113-173.

PleszCYNSKA, W. K. 1978. Microgeographic prediction of polygyny in the Lark Bunting. Science 201:935-937.

Proctor-Gray, E., AND R. T. Holmes. 1981. Adaptive significance of delayed attainment of plumage in male American Redstarts: tests of two hypotheses. Evolution 35:742-751.

Ratcliffe, L. M. 1981. Species recognition in Darwin's Ground Finches (Geospiza, Gould). Ph.D. Dissertation. McGill Univ.

Ratcliffe, L. M., and P. R. Grant. 1983. Species recognition in Darwin's Ground Finches (Geospiza, Gould). 1. Discrimination by morphological cues. Anim. Behav. 31:1139-1153.

Rohwer, S., S. D. Fretwell, and D. M. Niles. 1980. Delayed maturation in passerine plumages and the deceptive acquisition of resources. Amer. Natur. 1 15:400-437.

Rohwer, S., AND F. C. Rohwer. 1978. Status signalling in Harris Sparrows: experimental deception achieved. Anim. Behav. 26:10121022.

SeArCy, W. A. 1979a. Male characteristics and pairing success in Red-winged Blackbirds. Auk $96: 353-363$.

- 1979b. Morphological correlates of reproductive success in captive male Red-winged Blackbirds. Condor 81:417-420.

- 1979c. Female choice of mates: a general model for birds and its application to Redwinged Blackbirds (Agelaius phoeniceus). Amer. Natur. 114:77-100.

SElander, R. K. 1972. Sexual selection and dimorphism in birds, p. 180-230. In B. Campbell (ed.), Sexual Selection and the Descent of Man 1871-1971. Aldine, Chicago.

VERNER, J. 1977. On the adaptive significance of territoriality. Amer. Natur. 111:769-775.

WADE, M. J., AND S. J. ARNold. 1980. The intensity of sexual selection in relation to male sexual behaviour, female choice, and sperm precedence. Anim. Behav. 28:446-461.

Wittenberger, J. F. 1981. Male quality and polygyny: the 'sexy son' hypothesis revisited. Amer. Natur. 117:329-342.

ZAHAVI, A. 1977. The cost of honesty (further remarks on the handicap principle). J. Theoret. Biol. 67:603-605.

Corresponding Editor: R. Ricklefs

\section{APPENDIX}

Sexual selection on Geospiza scandens.-As in $G$. fortis the sex ratio in $G$. scandens has been skewed towards males since 1977 (Millington and Grant, 1983). The potential for sexual selection was as great as in $G$. fortis, as shown by a partitioning of the components of potential selection (Table Al). $G$. scandens differs in being less variable in both body size and in rate of plumage acquisition: only two out of 39 males $(5 \%)$ were not in full adult plumage by their third year. There was no significant directional selection on male body size accompanying the mortality of 1977 and no directional sexual selection in 1979 or 1980 (Table A2). However it is notable that there was stabilizing selection on beak length over the period of mortality (Grant and Price, 1981) and the variance decrease for this character under sexual selection in 1979 was close to significance $(P=.06$, two-tailed Levene test). Directional sexual selection was observed in 1981, but this was not preceded by substantial mortality.

Among the males hatched in 1978, those with more fully adult plumage were favored as mates in 1980 (probit, $N=45, \chi^{2}=6.8, P=.009$ ). Geospiza scandens differs from $G$. fortis in holding defined territories throughout the year; female choice may be based on cactus quality which is important for survival and early breeding (Millington and Grant, 1983). In 1979, area of cactus correlated with male 
size but mating success did not. A more direct measure of territory quality (number of cactus fruits) correlated with mating success but not male size
(Millington and Grant, 1983). Territory area and other variables have not been measured in subsequent years.

TABLE A1. Statistics on mating and fledging success in Geospiza scandens. Conventions and comparisons as in Table 3.

\begin{tabular}{crcccccccr}
\hline \hline Year & $N$ & $N m$ & l's & \multicolumn{1}{c}{$I s$} & $\bar{x}$ & $I m$ & If & $I s / I m$ & $I m / I f$ \\
\hline 1979 & 62 & 25 & .24 & 1.50 & .89 & 2.80 & .28 & .54 & 10.0 \\
1980 & 104 & 50 & .25 & 1.09 & .66 & 2.73 & .80 & .40 & 3.4 \\
1981 & 98 & 58 & .24 & .70 & 1.62 & 1.13 & .13 & .62 & 8.7 \\
\hline
\end{tabular}

TABLE A2. Size selection in Geospiza scandens. All conventions and comparisons are as used in Table 4. With the exception of wing length, which was significantly less variable among the mated males than the unmated males in $1980(P<.05)$, there were no significant differences in the variance for any character (Levene tests).

\begin{tabular}{|c|c|c|c|c|c|c|}
\hline & \multicolumn{2}{|c|}{1979} & \multicolumn{2}{|c|}{1980} & \multicolumn{2}{|c|}{1981} \\
\hline & Not mated & Mated & Not mated & Mated & Not mated & Mated \\
\hline Weight & $21.41^{*}$ & $22.71^{*}$ & 21.66 & 21.18 & 21.16 & 21.63 \\
\hline Wing & 74.42 & 74.88 & 74.38 & 74.40 & 73.00 & 73.64 \\
\hline Beak length & 14.69 & 14.85 & 14.89 & 14.54 & 14.39 & 14.64 \\
\hline Beak depth & 9.47 & 9.59 & 9.56 & 9.41 & $9.33^{*}$ & $9.55^{*}$ \\
\hline Beak width & 8.90 & 8.88 & 8.89 & 8.89 & $8.69^{*}$ & $8.95^{*}$ \\
\hline Sample size & 41 & 16 & 16 & 25 & 35 & 25 \\
\hline
\end{tabular}

